\title{
An Experience Using Performance-Centered Mobile Learning to Enhance Fieldwork Education
}

\author{
$\underline{\text { http://dx.doi.org/ijac.v4i4.1727 }}$ \\ S. Stoyanova-Petrova \\ Plovdiv University, Plovdiv, Bulgaria
}

\begin{abstract}
Mobile performance support system (mPSS) focuses on helping students to perform an authentic task with minimum support of others, providing them with sufficient information such as expert advice and procedures, just-intime. Providing this support on a mobile device enables students to make their learning more efficient and relevant. Fieldwork has long been identified as providing students undertaking professional studies with a means of implementing theory into real life situations. In many ways there is a natural link between fieldwork and mobile technology. This paper reports our experience using performancecentered mobile learning to enhance active, fieldwork education and the investigation of its impact on students learning. Fieldwork education is vital for many engineering courses. Two case studies held outside the classroom are presented. In the first case, the students are admitted to the technical equipment in a base station of a Bulgarian mobile operator outside the city of Plovdiv. In the second case, students visit an electronics manufacturing plant and directly inspect the production process.
\end{abstract}

Index Terms-Fieldwork education, higher education, mobile learning, performance-centered learning, technology enhanced learning.

\section{INTRODUCTION}

In a performance-centered approach to learning this would mean that students are instructed to perform an authentic task, related to their future job, and are provided with access to a full range of information such as data, images, advices, tools, assessment and monitoring systems [1], while performing this task. As a new technology, performance-centred educational systems have a strong potential to help students mastering job-related skills and to perform the task at hand with minimum support provided by others. One medium through which this support and information can be provided is a mobile device. Mobile technologies offer the opportunity to embed learning in a natural environment. Mobility helps students to maximize learning time and to learn anywhere, anytime. Integrating performance-centered learning and mobile learning (mlearning), results in a performance-centered mobile learning approach, in which students receive performance support via a mobile device when performing job-related tasks.

Fieldwork has long been identified as providing students undertaking professional studies with a means of implementing theory into a real life context [2]. Fieldbased learning encourages curiosity, motivation and group interaction [3]. Fieldwork is one way of improving effec- tive learning and raising learning retention, particularly if it is "active", where learners participate in observations and recording, rather than passive fieldwork where students watch the teacher [3].

Lonergan and Andresen [4] suggest that the uniqueness of field experience results from:

- providing opportunities for practicing techniques that cannot be carried out elsewhere,

- demonstrating/illustrating objects or phenomena not accessible in other settings, enabling direct contact with, perception of or interaction with them,

- stimulating higher level understanding of matter encountered elsewhere,

- stimulating an attitude of appreciation, concern and valuing of particular environments encountered in the field.

The student's experience and cognition during and after fieldwork provides deep learning - an orientation towards understanding, personal sense-making and active learningwhich will achieve better learning outcomes than the surface approaches of memorization, reproduction of knowledge and lack of personal engagement which typify the traditional didactic model of education [2].

In many ways there is a strong link between fieldwork and mobile devices, which can act as a powerful support tools in most environments. Naismith et al. [5] noted that the potential of mobile technologies to transform our educational practices by moving learning outside the classroom, allowing learners to connect to resources and people anywhere, fostering collaboration and teamwork, and turning students into investigators through the publication of their observations. Mobile outside classroom learning potentially extends the scope of learning activities. Herrington and Herrington [6] noted that the particular suitability of mobile technologies for active learning, for example, "as tools for complex and sustained tasks and problem solving". Mobile technology can facilitate observation, data collection, group communication, and problem solving in the field. It could significantly boost motivation as well as the outcomes of learning.

One of the typical specific fields where the educational process may greatly benefit by a mobile technology that enables interactive outdoor distance learning is industrial engineering [7]. Guided visits to industrial plants can be organized with the help of mobile devices that allow students directly to inspect the production process, along with an on-line help provided by mobile devices. Moreover, Web-based mobile learning environments can also 
permit the students to perform supervised laboratory activities in industrial environment.

Engineering education draws on a range of underpinning subject areas and cognate disciplines and is characterized by laboratory based teaching, industrially based projects. There is by necessity a close relationship with industry, as engineering students need to apply their technical, management and business skills in an industrial context.

This paper reports an experience using performancecentered mobile learning to enhance active, fieldwork education and the investigation of its impact on students learning. Two case studies held outside the classroom are presented. In the first case, the students are admitted to the technical equipment in a base station of a Bulgarian mobile operator outside the city of Plovdiv. In the second case, they visit electronics manufacturing plant and directly inspect the production process. As a result students reported that the use of mobile technology in their study enhanced their readiness for tomorrow's workplace.

\section{M-FIELDWORK: A BRIEF REVIEW}

Many examples of $\mathrm{m}$-fieldwork in the educational setting come from the health sciences, usually from projects with medical students, but also from students of nursing, pharmacy and occupational therapy [8]. The substantial investment in healthcare and healthcare training has supported their implementation. KNOWMOBILE [9] was a PDA health training case study aimed at developing and evaluating net-based and mobile solutions for knowledge access in distributed training. The focus was on the medical students' needs for just-in-time knowledge in training situations in hospitals, as well as at home and while commuting to their workplace. The main findings from the KNOWMOBILE project pointed to several factors that act as barriers to widespread use of PDAs. First, only few web sites were adapted to the PDA screen size, and hence they are not very usable in terms of overview, and interaction. Second, field experiments showed that students experienced problems in working across different applications and information resources on the PDA. In addition, the high quality of the communication infrastructure in the hospitals- availability of stationary PCs, SMS via cellular phones, rapid and systematic paging systems- was a third factor in their non-use.

In the paper [10] the GIPSY project and its successor, the Manolo project are described. Both projects examined educational applications of mobile technology. GIPSY (Geo-Information for Integrating Personal Learning Environments) was an m-learning project in the domain of GIS, including two courses in which students used PDAs to collected field data, analyze it back in their labs, and then check the results again in the field. The Manolo project, built on the GIPSY project's experience, focussed on the integration of electronic, wireless and mobile learning. Despite problems, again with usability, performance and battery-life, both projects were successful. Feedback from students and teachers was very positive. Communication - both teacher - student and student - student - found new channels and opportunities within mobile learning.

The paper [2] reports on an investigation in Australia to introduce mobile support into the study of information systems in the field. The students used PDAs and other mobile devices to capture data about information systems in use outside the laboratory. The data was then used in classroom presentations. The main learning objective of the exercise was to get students very quickly interested in, and thinking about, information systems early on in their study. Fieldwork was chosen in preference to investigations in the artificial environment of the laboratory as a way of forcing students to consider the complexity of systems in their context of use. The major problem with the trial was the poor usability of the PDAs which made it hard for students to learn to use them quickly. The main conclusion from this project was that device selection is crucial for the success of $\mathrm{m}$-fieldwork activities, and educational design should encourage students to use their own mobile devices which would be more familiar to the students and simpler to use. However, the whole concept of $\mathrm{m}$-fieldwork was shown to be a great success. Introducing mobile support into an active and real-world learning exercise can only make it more contemporary and of greater interest to students whose means of communication is now firmly centered on this technology.

The article [11] focuses on mobile computing with a tablet PC, drawing from over five years of experience teaching with tablets in outdoor, field-based classes in the USA. Three classes are discussed- Environmental Science, Ecology, and Biology. The classes used standard off-the-shelf software or freeware, typically on Windowsbased desktop machines. The pen-enabled tablet allowed easy on-screen annotation and note-taking, and the software used had built-in digital inking capability. The experiment showed that, the tablet PCs worked well, acting as a data collection device so that students could record their observations and analyses while still in the field. Using this mobile computing method, there was no need to download and post-process waypoints, hand-written notes, or sketches because these data were already documented in a fully functioning computer. The conclusion was that a tablet PC taken outside the walls of a classroom could work for all sorts of courses that take students into the field. Negative comments typically revolved around hardware failures, such as short battery life and slow computer speed, but also noted difficulties with the specialized software.

\section{MDIPSEIL SYSTEM}

MDIPSEIL is a performance-centered mobile learning environment. It was based on the existing e-learning environment, DIPSEIL - performance-centred e-learning management system [12]. The instructional design of DIPSEIL and mDIPSEIL courses was based on the principles of performance support system (PSS), including a task description, task-specific training, reference information, instructions how to perform, and expert advices. DIPSEIL has two specific characteristics:

- The learning content is based on learning tasks. Performance tasks aim preliminary at specified learning outcomes.

- There will be no lectures, practical or final examination. Students only perform the learning tasks throughout the semester and collect credits for each learning tasks they perform adequately. They receive a final mark at the end of the semester based on the collected credits. 


\section{A. Instructional design for performance-centered m- learning}

It is important that the existing course is developed according to the principles of performance support for learning. First, it is important that the performance in education that is supported is related to performance in students' future working environments. During the course, students should be confronted with and trained for situations they will also encounter in their future profession:

- Identify the reference situation of a particular course. These are the professional settings where students are going to apply in practice what they have learned during the course.

- Define a set of authentic problems and develop tasks related to a specific working environment.

- Shift the instructional focus from knowledge and understanding (i.e., the lower levels of the learning taxonomy), towards solving real-world problems (i.e., the higher levels of the learning taxonomy).

- Applying adequate summative performance-oriented assessment methods.

\section{B. Software Concepts}

mDIPSEIL is a web system, developed in PHP [13]. It uses the well known database engine - MySQL. Its ease of use, the high level of security and its free use have made this engine one of the best "data stations" in the world. Everything in the mDIPSEIL system is stored in the database - from the organization of the system, through the educational data and until the multimedia files. The whole architecture of the educational system is represented as tables in the database engine, which ensures the right organization of the system. Tasks, Modules and Courses are stored in separate tables, which contain only the most important information about them. mDIPSEIL system uses the free Apache web server, which plays the role of "glue" for the whole system.

\section{Course structure}

Similar to DIPSEIL, mDIPSEIL system has the following structure: courses, containing modules and containing tasks. In this new system a new level was integrated in this structure, called "Objects". Objects are the building elements of the tasks. Objects can be: text, picture, sound or video. One task may have as many objects as the teacher wants. One object can be used not only in one task, but in as many tasks as there are in the system, not only in the same module or course, but also in others and by other teachers. This brings the greatest power of the system - the sharing of objects.

With mDIPSEIL system creating, editing and viewing tasks has never been easier. Teachers are the persons who create tasks. The first step for the new teacher is to create new courses, modules and tasks. In each task the content is structured thus:

- Task description,

- Task-specific training,

- Reference information,

- Instructions how to perform the task,

- Expert advices about a task.

Task description describes the task that the user has to perform.
Task-specific training reduces preliminary training by helping the user to learn while performing the task. This type of training is learner-centred because the learner asks for help when he needs it to perform a task, and the help gives him the specific information that she/he requests.

Rreference information supports the students by making immediately available information, which they previously had to memorize or look for in a book or a manual. The reference section allows the student to learn more deeply about a given task and is always available for her/him to read and provides the theory behind the task it supports.

Instructions how to perform includes instructor-worked out examples or solutions to problems. The students are provided with the steps that should be taken in order to solve the problem or complete the task.

Expert advices contains specific advices on performing tasks.

\section{Users}

In mDIPSEIL there are two types of users - students and teachers. Teachers use a specially developed web system for editing and importing educational content to the database system.Using this web system they may create and/or delete courses, modules, tasks and objects, assign objects to tasks or remove assignments, but only for tasks created by them. They can also specify how objects are used inside of tasks. For proper view of educational content teachers must also specify coordinates for the tasks and/or country for the task. Tasks in mDIPSEIL must be attached to tasks from DIPSEIL, or otherwise students will not be able to view them.

Students are actually the direct user of educational content through their mobile devices and thus the system is specially developed for them [14]. They use their mobile devices to login to a simplified web-based system [13]. Students are identified with unique e-mail and password from the DIPSEIL system. The mobile device should have an HTML-supporting web browser [13]. Once logged in, they may view all tasks, which they have chosen. The system's menu is always at the bottom of the screen and allows them to navigate through the different learning objects and to use available instruments (Fig.1). If there are videos or sounds, they will be presented as links, which students can download and study its contents.

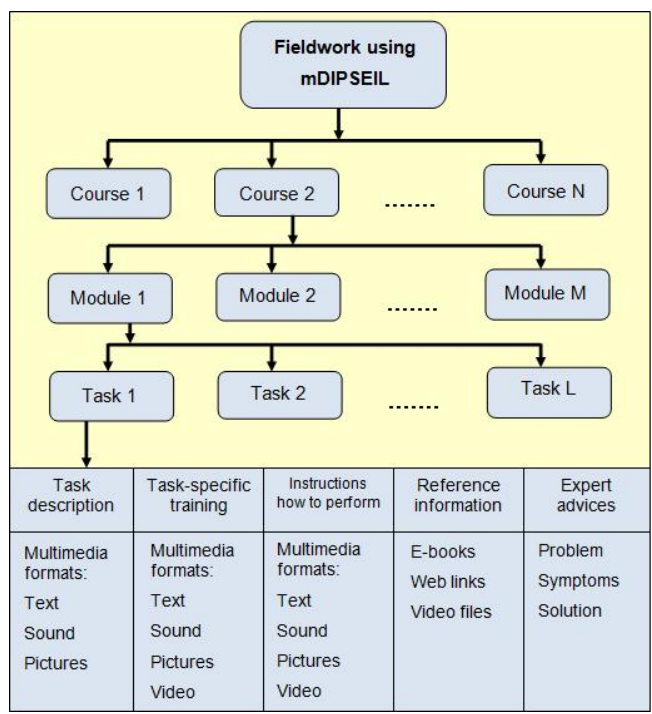

Figure 1. Fieldwork using mDIPSEIL 


\section{CASE STUDY ONE}

\section{A. About the Course}

In the first case "Mobile Communication Systems" course was presented for fourth year students from Information Physics and Communications specialty in the Physics Faculty at Plovdiv University.

The course presents mobile communications. Much of the discussion deals with cellular radio and extends this thinking inside and outside buildings. The coverage most necessarily includes propagation for the several environments, propagation impairments, and methods to mitigate those impairments, access techniques, bandwidth limitations, and ways around this problem. The course objective is to provide an appreciation of mobile/personal communications. Space limitations force us to confine the discussion to what might loosely be called "land mobile systems".

This study examines the learning experiences of 15 students within two tasks. The tasks which are chosen for the fieldwork learning purposes are „GSM Architecture“ and „GSM Network" as most appropriate for fieldwork training. The students are admitted to the technical equipment in a base station of a Bulgarian mobile operator outside the city of Plovdiv.

Task performance organization:

- The tasks are developed for mDIPSEIL;

- Each Task is performed in one week;

- Each task has a deadline;

- Students use PC and Internet to prepare and send task performance to the DIPSEIL server.

Some students used their own mobile phones, and other students are equipped with mobile devices by the teachers. These mobile devices are provided by the financial help of a European project. They are allowed to fulfill the tasks which they have in mDIPSEIL in real environmental conditions. Fig. 2 shows the Task description of the task GSM Network. In Fig. 3 and Fig. 4 one can see the Task specific training windows of the task, displayed on the student mobile device.

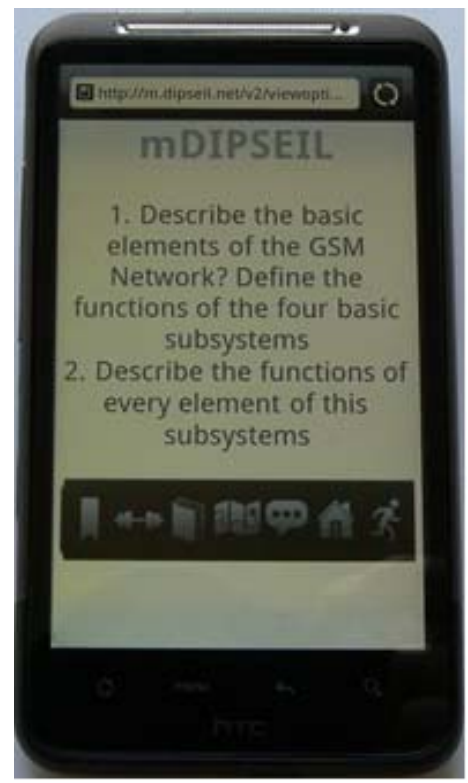

Figure 2. Task: GSM Network - Task description
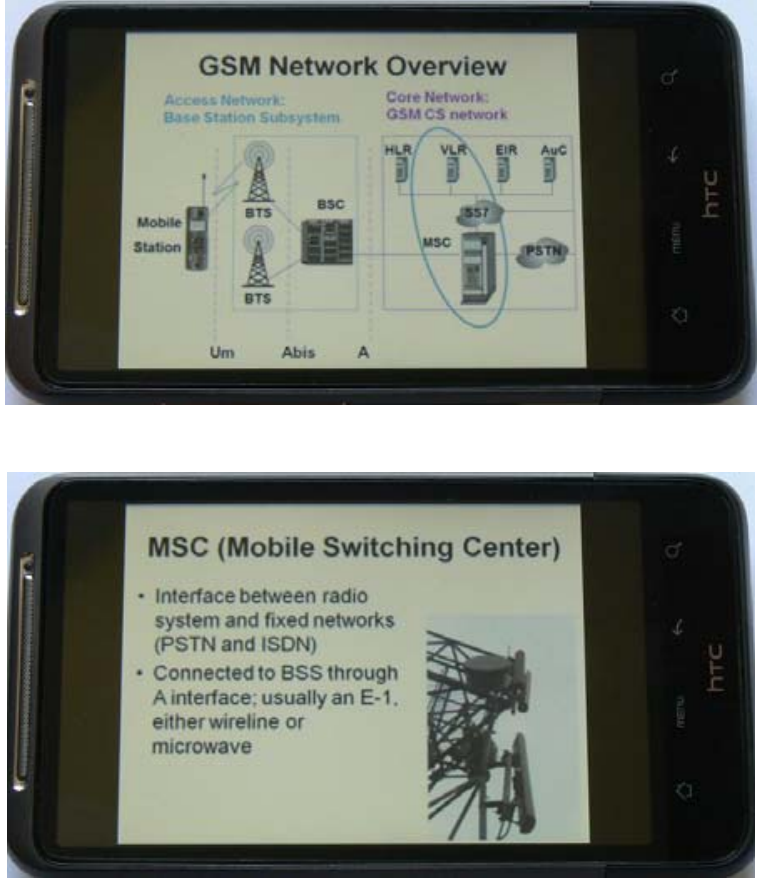

Figure 3. Task: GSM Network - Task-specific training

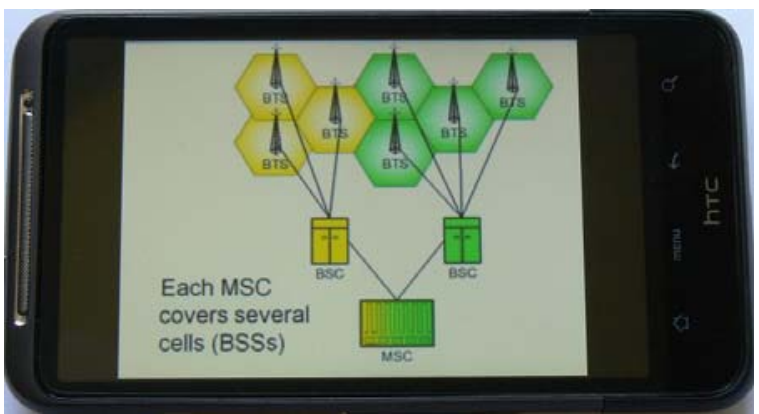

Figure 4. Task: GSM Network - Task-specific training

Students' reports reflect increased conceptual understanding of core concepts through hands-on learning activities supported by group work in the base station. The students appreciated the ability to gain their own experience in working in OMC (Operation and Maintenance Center).

\section{B. Course Evaluation}

After the experiments have been performed a questionnaire survey is given to evaluate the effectiveness of the mDIPSEIL in improving student learning motivation and effectiveness.

We give the students a post-course questionnaire using a Likert scale $(1=$ strongly disagree, $2=$ disagree, $3=$ neutral, $4=$ agree, $5=$ strongly agree). Fig. 5 shows the questions we asked on the post-course questionnaire to get a sense of how the students felt after taking „Mobile Communication Systems" course and the percentage of positive agreement (only answers 4 or 5 on the 5 -point Likert scale). Fifteen students have responded to the survey.

As can be seen in figure 5 four questions have the same high scores (93 percent either agreed or strongly agreed). 
PAPER

An Experience Using Performance-Centered Mobile Learning to Enhance Fieldwork Education

Q5: Taking the course by means of a mobile device helped me to view the course material at the moment I really needed it

One of the reasons for this is that students enjoyed the mobile device as a tool that brought greater flexibility into their learning and now they could learn anywhere anytime (see Table I). The only student who gave a neutral answer stated that he/she preferred to learn orally as the mobile learning "is more time consuming".

Q8. I understand the role that technology plays in fieldwork training

Students agreed that this technology, would be useful in fieldwork training (see Table II), but they were worried that the technology might be too expensive.

Q11. I have learned to synthesize and apply what I have learned from theory in the practice

We can say that the interest of students to the use of mobile phones have also helped them to integrate theory and practice (see Table III). The argument of the student who gave negative answer was that he/she preferred classroom education with PC.

Q15. I would take another mobile learning course, if available

Students think that mobile technology would be really helpful for other courses so they would like to take other lessons using mobile devices (see Table IV). They would recommend this technology although it is a little slow.

Students return strongly favorable responses on nearly all questions related to their attitude toward technology and science and questions about their confidence level. In particular students see value in working in teams (Q6), feel strong in their ability to synthesize and apply knowledge from theory to real base station environment work (Q11), and see the link between technology and training (Q8). We are pleased that 80 percent of our students feel prepared to enter a mobile communication company as a technician (Q9).

TABLE I.

\begin{tabular}{|l|l|l|}
\hline & Number & Percent \\
\hline $5=$ strongly agree & 4 & $27 \%$ \\
\hline $4=$ agree & 10 & $67 \%$ \\
\hline $3=$ neutral & 1 & $6 \%$ \\
\hline $2=$ disagree & 0 & $0 \%$ \\
\hline $1=$ strongly disagree & 0 & $0 \%$ \\
\hline
\end{tabular}

TABLE II.

\begin{tabular}{|l|l|l|}
\hline & Number & Percent \\
\hline $5=$ strongly agree & 11 & $73 \%$ \\
\hline $4=$ agree & 3 & $20 \%$ \\
\hline $3=$ neutral & 1 & $7 \%$ \\
\hline $2=$ disagree & 0 & $0 \%$ \\
\hline $1=$ strongly disagree & 0 & $0 \%$ \\
\hline
\end{tabular}

1. It was easy to navigate through the course on my mobile device.

2. I am confident in my technical background.

3. I have a solid background which will allow me to learn new technologies in a mobile base station environment.

4. Compared to other traditional courses I took, learning by means of a mobile device helped me better to learn the course material.

5. Taking the course by means of a mobile device helped me to view the course material at the moment I really needed it.

6. I see value in working in a team and collaborating with other students on different tasks.

7. I enjoy using technology in my training and work.

8. I understand the role that technology plays in fieldwork training.

9. I feel confident in my abilities to enter a mobile communication company as a technician.

10. I developed specific field skills in this course.

11. I have learned to synthesize and apply what I have learned from theory in the practice.

12. I have gained critical thinking skills through this course (e.g., ability to evaluate different technical methods, apply them to different situations).

13. Applying techniques we learned in classroom in real practical environment was valuable to me.

14. Using technology (mobile phones) was valuable to me.

15. I would take another mobile learning course, if available.

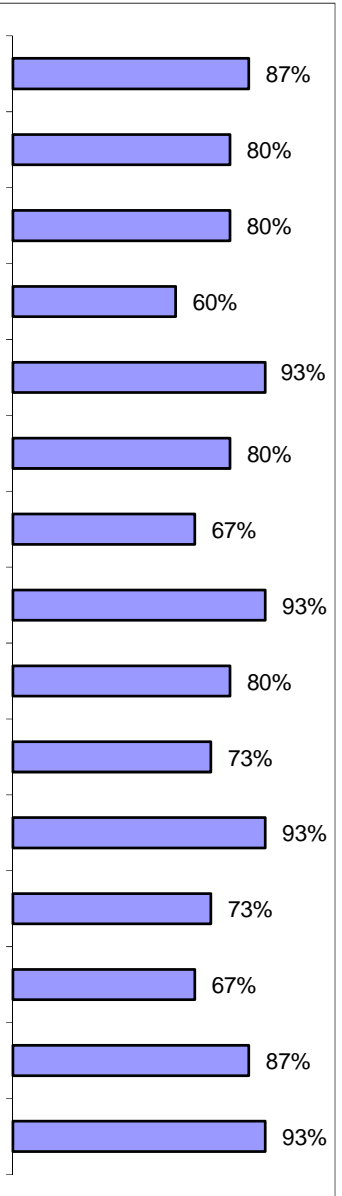

Figure 5. Results of Post-Course Survey in „Mobile Communication Systems“ 
PAPER

\section{CASE Study Two}

\section{A. About the Course}

In the second case "Foundations of technology and engineering design" course was presented for fourth year students from Engineering Physics specialty in the Physics Faculty at Plovdiv University. The goal of this course is to provide students a hands-on experience involving actual printed circuit board (PCB) design, layout, fabrication and assembly. The course was developed using the performance-centered learning model and meets the needs of continuing job-related training.

TABLE III.

\begin{tabular}{|l|l|l|}
\hline & Number & Percent \\
\hline $5=$ strongly agree & 7 & $47 \%$ \\
\hline $4=$ agree & 7 & $47 \%$ \\
\hline $3=$ neutral & 0 & $0 \%$ \\
\hline $2=$ disagree & 1 & $6 \%$ \\
\hline $1=$ strongly disagree & 0 & $0 \%$ \\
\hline
\end{tabular}

TABLE IV.

\begin{tabular}{|l|l|l|}
\hline & Number & Percent \\
\hline $5=$ strongly agree & 10 & $67 \%$ \\
\hline $4=$ agree & 4 & $27 \%$ \\
\hline $3=$ neutral & 1 & $6 \%$ \\
\hline $2=$ disagree & 0 & $0 \%$ \\
\hline $1=$ strongly disagree & 0 & $0 \%$ \\
\hline
\end{tabular}

This study examines the learning experiences of 16 students within two tasks. The tasks which are chosen for the fieldwork learning purposes are „Manufacture of Printed Circuit Boards (PCB's)“ and „Assembly of components on PCB's", both are part of the "Electronics Manufacturing Processes" module. Students visit electronics manufacturing plant in Plovdiv and directly inspect the production process. By using a mobile phone they can easily get interactive help and guidance how to use the tools or machine and access a knowledge database with known solutions for particular problems. Fig. 6 shows the Task description of the task ,Manufacture of Printed Circuit Boards (PCB's) “. In Fig.7 and Fig.8 one can see the Task specific training windows of the presented two tasks displayed on the student mobile device.

Some students used their own devices, usually mobile phones or PDAs and other students are equipped with mobile devices by the teachers. These mobile devices are provided by the financial help of a European project.

Task performance organization is just the same as in case one.

Students were divided into small groups of 4 students each. They used their mobile devices to learn, take photographs or make video recordings of the production process and make notes with a stylus or keyboard. Then the collected information is used by them to perform the tasks.

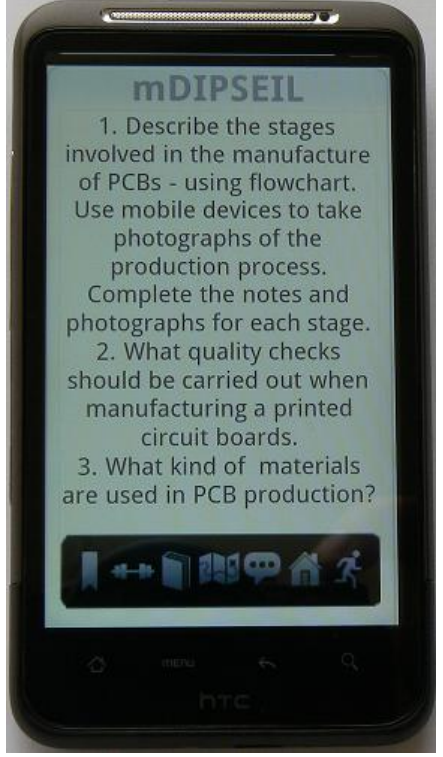

Figure 6. Task: Manufacture of Printed Circuit Boards - Task description
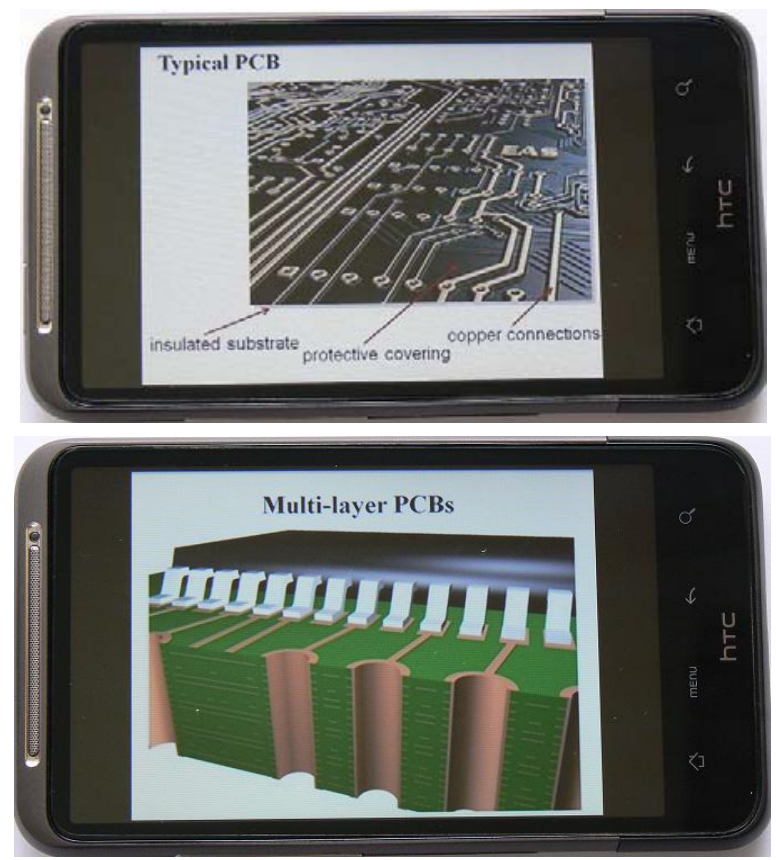

Figure 7. Task: Manufacture of Printed Circuit Boards - Task-specific training

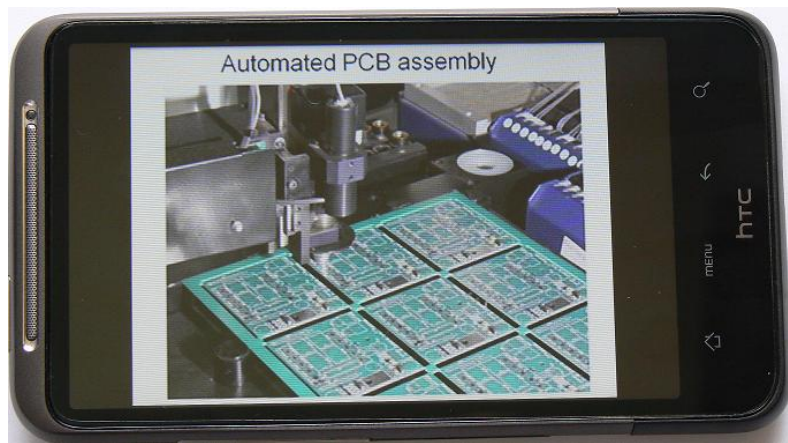

Figure 8. Task: Assembly of components on PCB's - Task-specific training 
PAPER

AN EXPERIENCE USING PERformanCE-CENTEREd MOBILE LEARNING to ENHANCE FIELDWORK EdUCATION

\section{B. Course Evaluation}

The post-course questionnaire was given after the two tasks performance using a Likert scale $(1=$ strongly disagree, 2 = disagree, $3=$ neutral, $4=$ agree, $5=$ strongly agree) and collected their opinion. Sixteen students have responded to the survey. Fig. 9 shows the questions we asked and the percentage of positive responses (only answers 4 or 5 on the 5-point Likert scale). The results are close to those of case one. Students indicate that this fieldwork enhanced the relationship among team members. As for the performance of the mDIPSEIL, students regard it as a good assistant in conducting fieldwork and point out its easy user interface.

Detailed answers to some of the questions are listed below.

Q1. It was easy to navigate through the course on my mobile device

Eighty-eight percent of the students indicated that it was easy to navigate through mDIPSEIL and to view graphics and presentations (see Table V).

\section{Q7. I enjoy using technology in my training and work}

Sixty-nine percent of the students enjoyed the idea of using a mobile device for learning (see Table VI). One student who didn't agree made a comment that mobile phone is not really as useful as the computer is.
Q14. Using technology (mobile phones) was valuable to me

Eighty-eight percent of the students agreed that mobile phones were valuable to them. They would like to see more workplace videos (see Table VII). The majority of the negative comments were about the download speed.

TABLE V

\begin{tabular}{|l|l|l|}
\hline & Number & Percent \\
\hline $5=$ strongly agree & 10 & $63 \%$ \\
\hline $4=$ agree & 4 & $25 \%$ \\
\hline $3=$ neutral & 2 & $12 \%$ \\
\hline $2=$ disagree & 0 & $0 \%$ \\
\hline $1=$ strongly disagree & 0 & $0 \%$ \\
\hline
\end{tabular}

TABLE VI.

\begin{tabular}{|l|l|l|}
\hline & Number & Percent \\
\hline $5=$ strongly agree & 4 & $25 \%$ \\
\hline $4=$ agree & 7 & $44 \%$ \\
\hline $3=$ neutral & 4 & $25 \%$ \\
\hline $2=$ disagree & 1 & $6 \%$ \\
\hline $1=$ strongly disagree & 0 & $0 \%$ \\
\hline
\end{tabular}

TABLE VII.

\begin{tabular}{|l|l|l|}
\hline & Number & Percent \\
\hline $5=$ strongly agree & 8 & $50 \%$ \\
\hline $4=$ agree & 6 & $38 \%$ \\
\hline $3=$ neutral & 1 & $6 \%$ \\
\hline $2=$ disagree & 1 & $6 \%$ \\
\hline $1=$ strongly disagree & 0 & $0 \%$ \\
\hline
\end{tabular}

1. It was easy to navigate through the course on my mobile device.

2.I am confident in my technical background.

3.I have a solid background which will allow me to learn new technologies in PCB manufacturing.

4. Compared to other traditional courses I took, learning by means of a mobile device helped me better to learn the course material.

5. Taking the course by means ofa mobile device helped me to view the course material at the momentI really needed it.

6.I see value in working in a team and collaborating with other students on differenttasks.

7.I enjoy using technology in my training and work.

8.I understand the role that technology plays in fieldwork training.

9.I feel confident in my abilities to enter an electronics manufacturing plant as a PCB designer.

10.I developed specific field skills in this course.

11.I have learned to synthesize and apply what I have learned from theory in the practice.

12.I have gained critical thinking skills through this course (e.g., ability to evaluate different technical methods, apply them to different situations).

13. Applying techniques we learned in classroom in real practical environmentwas valuable to me.

14. Using technology (mobile phones) was valuable to me.

15. I would take another mobile learning course, if available.

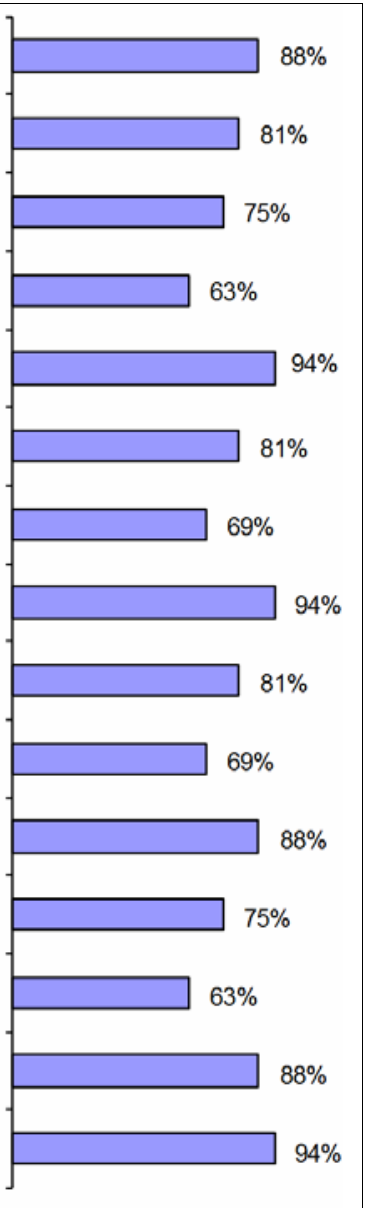

Figure 9. Results of Post-Course Survey in „Foundations of technology and engineering design“ 


\section{CONCLUSIONS}

This paper reports our experience in embedding performance-centered mobile learning in fieldwork education of engineering students. Our conclusions are:

- Most students think that the mDIPSEIL is easy to use and useful in learning. Therefore, they endorsed the use of the mDIPSEIL for future learning.

- Overall, the students liked the interactive activities and the quality of the tasks.

- mDIPSEIL gives teachers and students new perceptions of doing fieldwork. Teachers regard mDIPSEIL as a useful tool for assisting students in the whole learning process.

- Performance-centered mobile learning in fieldwork education increases the conceptual understanding of core concepts.

The experiment was greatly appreciated by students. Taking into account this result, we plan to make the mobile fieldwork a permanent component of student education in these two courses.

\section{REFERENCES}

[1] B. Raybould,"Solving human performance problems with computers. A case study: Building an electronic performance support system," Performance and Instruction, vol. 29, no.10, pp. 4-14, 1990. http://dx.doi.org/10.1002/pfi.4160291004

[2] L. E. Dyson, E. Lawrence, A. Litchfield and A. Zmijewska, "Mfieldwork for information systems students," Proceedings of the 41st Annual Hawaii International Conference on System Sciences (HICSS 2008), pp.46, 2008. http://dx.doi.org/10.1109/ HICSS.2008.236

[3] M. Manning, J.A. Harris, W.A. Maher and K.G. McQueen, "Learning in the Field: A Manual for Conducting Field Classes," Gold Guide, Vol. 5, ACT: HERDSA, 1998.

[4] N. Lonergan and L.W. Andresen, "Field-based Education: Some Theoretical Considerations," Higher Education Research and Development, vol.7, no. 1, pp. 63-77, 1988. http://dx.doi.org/10.1080/ 0729436880070106

[5] L. Naismith, P. Lonsdale, G. Vavoula and M. Sharples, "Literature review in mobile technologies and learning," NESTA Futurelab Report 11, Bristol, UK: NESTA Futurelab, 2004.
[6] A. Herrington and J. Herrington, "Authentic mobile learning in higher education," Australian Association for Research in Education (AARE) 2007 Conf., pp. 1-9, 2007.

[7] M. Roccetti, P. Salomoni, V. Ghini and G. Pau, "Interactive outdoor web-based distance learning using mobile terminals," in the Proceedings of the International Conference on Simulation and Multimedia in Engineering/Western MultiConference on Computer Simulation (ICSEE/WMC'2001), in H. Vakilzadian (Ed.), The Society for Computer Simulation International Phoenix, USA, 2001.

[8] K. Sommers et al., "Little Guys Make a Big Splash: PDA Projects at Virginia Commonwealth University," SIGUCCS '01, October, Portland, Oregon, 2001, pp. 190-193.

[9] O. Smordal and J. Gregory, "Knowmobile: Mobile opportunities for medical students," in Mobile Learning: A handbook for educators and trainers, A. Kukulska-Hulme and J. Traxler, Eds. Routledge, Milton Park, 2005, pp. 99-105.

[10] P. Wentzel et al., "Using Mobile Technology to Enhance Students' Educational Experiences," ECAR Case Study 2, EDUCAUSE, Boulder, Colorado, 2005, pp. 1-18.

[11] M. Stewart et al., "The Educational Potential of Mobile Computing in the Field," EDUCAUSE Quarterly Magazine, vol. 34, no.1, 2011.

[12] http://www.dipseil.net .

[13] D. Keegan et al., Mobile Learning Performance Support System For Vocational Education And Training. Plovdiv, 2010, Available: http://mpss.dipseil.net .

[14] http://m.dipseil.net/v2 .

\section{AUTHORS}

S. Stoyanova-Petrova is an Assistant Professor at the ECIT Department of University of Plovdiv, Bulgaria (email: sstoyanova@dipseil.net). She has a doctorate in Computing, scientific specialty "Automation of nonmaterial areas (education, science)" and Master of Science in Computer systems and technologies. Dr. Stoyanova is engaged with Web-based engineering education, mlearning, development of Internet-based PSS. Programming in PHP, MySQL, HTML, JavaScript, C, C++.

Received 28 June 2011. Published as resubmitted by the author 15 October 2011 . 